\title{
Simultaneous cyclization and derivatization of peptides using cyclopentenediones
}

\author{
Omar Brun, ${ }^{a}$ Lewis J. Archibald, ${ }^{\mathrm{b}}$ Jordi Agramunt, ${ }^{\mathrm{a}}$ Enrique Pedroso ${ }^{\mathrm{a}, \mathrm{c}}$ and Anna Grandas ${ }^{\star, a, c}$ \\ ${ }^{a}$ Departament de Química Inorgànica i Orgànica (secció Q. Orgànica, and IBUB ${ }^{c}$ ), Facultat de Química, Universitat de \\ Barcelona, Martí i Franquès 1-11, 08028 Barcelona, Spain. \\ ${ }^{b}$ University of Glasgow, Glasgow G12 8QQ, Scotland, United Kingdom
}

anna.grandas@ub.edu

Received Date (will be automatically inserted after manuscript is accepted)

\section{ABSTRACT}

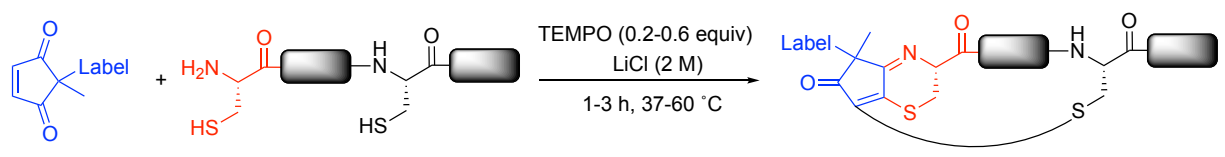

Unprotected linear peptides containing $\mathbf{N}$-terminal cysteines and another cysteine residue can be simultaneously cyclized and derivatized using 2,2-disubstituted cyclopentenediones. High yields of cyclic peptide conjugates may be obtained in short reaction times using only a slight excess of the cyclopentenedione moiety under TEMPO catalysis and in the presence of $\mathrm{LiCl}$.

Cyclic peptides have found wide application in the biological and medicinal fields. These compounds have been investigated to inhibit amyloid fibrillation, ${ }^{1}$ as antibacterial $^{2}$ and antifungal ${ }^{3}$ agents, in the treatment of tumours $^{4}$ and to regulate protein-protein interactions through epitope mimicking, ${ }^{5}$ among others.

Further functionalization of cyclic peptides can ameliorate their properties or those of the molecule to which they are attached. For example, conjugation to proteins $^{6}$ may enhance protein transduction, and conjugation to fluorophores ${ }^{7}$ is important to obtain traceable systems. As for cyclic RGD peptides, which are widely utilized to selectively target some cancer cells, they need to be conjugated to drugs, other biomolecules or radiolabels to be used in cancer therapy and diagnosis. ${ }^{8}$ For these reasons, methodologies allowing for the simultaneous cyclization and derivatization of peptides are of great interest, and in the last decade different groups have conducted research in this area. ${ }^{9}$

We have recently described that 2,2-disubstituted cyclopent-4-ene-1,3-diones (CPDs) selectively react with $N$-terminal cysteines in the presence of other cysteines. ${ }^{10}$ After formation of the Michael-type adduct (with a mass of $\mathbf{M ~ D a ) , ~ i n t r a m o l e c u l a r ~ i m i n e ~ f o r m a t i o n ~}$ furnishes an intermediate (M-18 Da adduct), which is subsequently oxidized (likely by oxygen) to generate a conjugated structure with a mass of M-20 Da that exhibits a UV maximum at $330 \mathrm{~nm}$ (Scheme 1).
Scheme 1. Outcome of the reaction between CPDs and $\mathrm{N}$ -

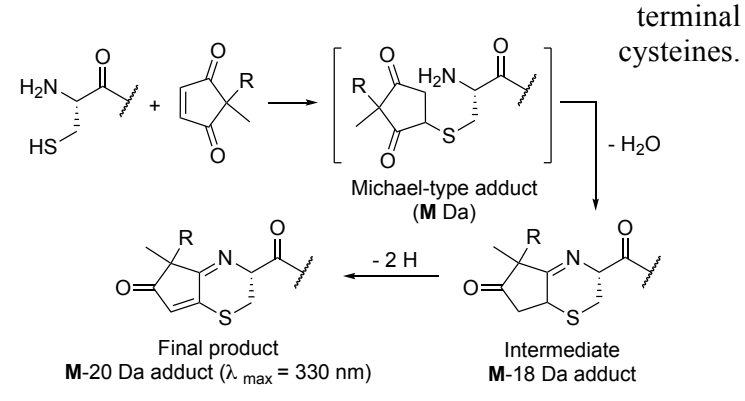

Since the M-20 conjugated adducts may undergo a second nucleophilic addition, we decided to explore the possibility of cyclizing peptides through reaction with another cysteine in the same peptide chain (Scheme $2 a$ ).

This manuscript describes different steps of the optimization of the cyclization reaction, which may provide labeled cyclic peptides in cases where suitably derivatized CPDs are used. Parameters affecting the reaction outcome and kinetics have been optimized, and product stability has been examined. In all cases formation of a cyclic molecule was confirmed by mass spectrometry and UV spectroscopy, and NMR proof was 
Scheme 2. a) Different steps in the intramolecular cyclization reaction ( $\mathbf{M}$ is the mass of the Michael-type adduct that would be generated by a simple CPD-thiol addition, see Scheme 1). R may incorporate a labeling moiety, see Figure 1). b) Major side products formed (oligomers were not observed, probably because of the high dilution reaction conditions). c) Cyclic peptide $3 \mathbf{a}$.
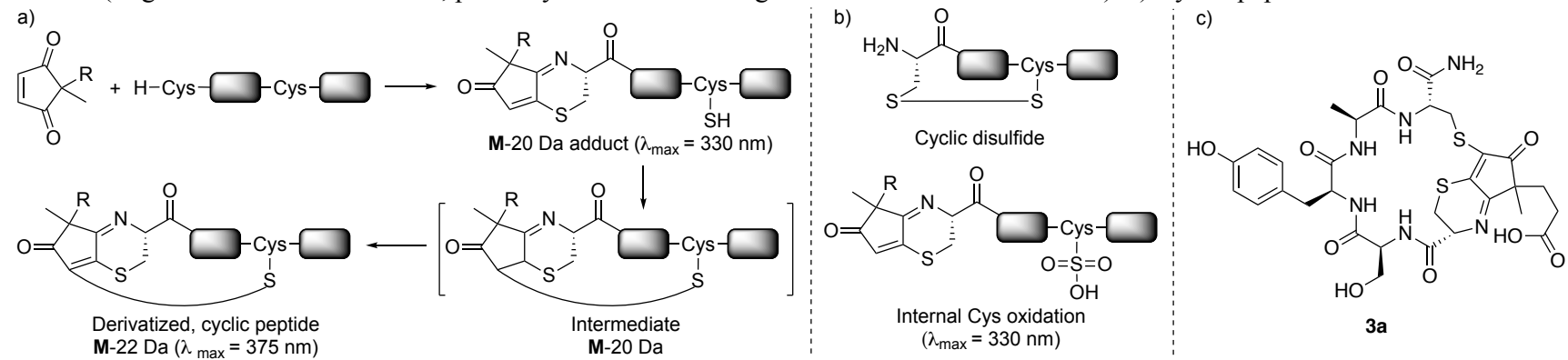

obtained for one peptide. The M-20 cyclic precursor (Scheme 2a) was occasionally detected (HPLC-MS).

Figure 1 assembles the structures of the CPDs and peptides utilized in the different cyclization reactions. In addition to model compounds such as peptides 1-4 and CPD a, CPDs carrying biotin and dansyl labeling moieties (b and $\mathbf{c}$, respectively), the linear precursors of oxytocin $^{11}(5)$ and a bombesin agonist ${ }^{12}(6)$, and epimeric peptides 7-9 (see below for an explanation) were used.

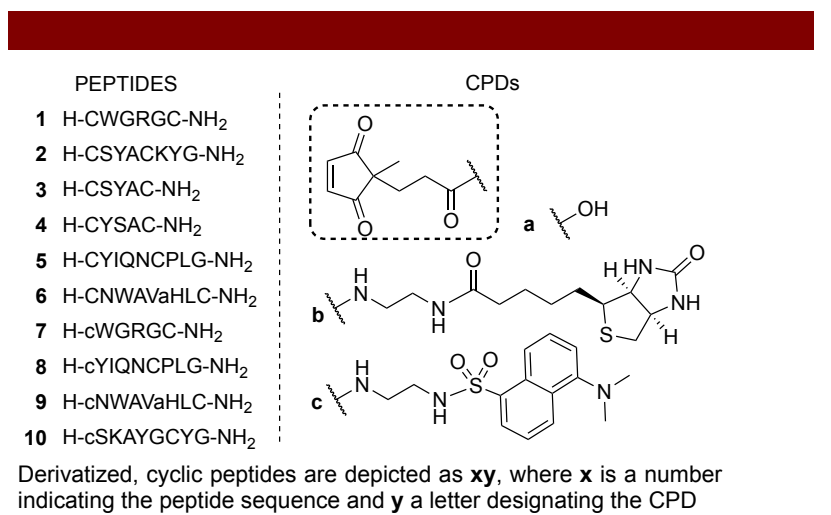

Figure 1. Structures of the different peptides and CPDs used in this work. Lower case letters describe D-amino acids.

In preliminary experiments, aqueous solutions of CPD a and peptides 1 or 2 were heated $\left(60^{\circ} \mathrm{C}\right)$, and formation of the two expected diastereomeric cyclic adducts (differing in the configuration of $\mathrm{C} 2$ in the $\mathrm{CPD}$ ring) was confirmed by the appearance of two peaks with a mass of M-22 Da (HPLC-MS analysis) and a UV maximum around $375 \mathrm{~nm}$ (see Scheme 2a). However, both crudes, and especially that of 1a, were rather complex, which evidenced that cyclization conditions had to be fine-tuned.

In an attempt to accelerate the reaction, $\mathbf{1}$ and $\mathbf{a}$ were reacted under conditions enhancing the nucleophilicity of thiol groups, at $\mathrm{pH}=8$ (phosphate buffer) and in the presence of 1-2 equiv of different bases $\left(\mathrm{NaOH}, \mathrm{Et}_{3} \mathrm{~N}\right)$.
Yet, these experiments rendered complex crudes, with the undesired disulfide as the main product (Scheme $2 b$ ).

Prompted by the fact that some thiol-involving conjugate additions are radical reactions, ${ }^{13}$ the addition of 2,2,6,6-tetramethyl-1-piperidinyloxy (TEMPO) and $\mathrm{O}_{2}$ (balloon) was assayed. TEMPO provided better results than $\mathrm{O}_{2}$, although formation of the cyclic disulfide and the product with the internal cysteine oxidized (see Scheme 2b) were observed as competing side-reactions. Therefore, the protocol for TEMPO addition (amount and timing) together with peptide concentration, CPD excess and reaction temperature were adjusted to reduce the amount of by-products.

With the so far best-working conditions (protocol 1, Supporting Information (SI), section 4) cyclic peptides 1a and 2a could be satisfactorily obtained employing only 0.4 equiv of TEMPO (80-85 \% HPLC-based yield; see entries 1 and 2 of Table 1). In parallel with these experiments, the $\mathbf{3}+\mathbf{a}$ reaction was carried out at a higher scale (SI, section 5). Both diastereomers of cyclic peptide 3a (Scheme 2c, M-22 Da products) were isolated by HPLC and fully characterized by NMR. HMBC experiments allowed to observe the correlation between the olefin carbons of the CPD ring and the $\beta$ hydrogens of both the $C$ - and $N$-terminal cysteines, confirming that cyclization had taken place.

The conjugated system generated upon cyclization was found to contribute to the peptide absorbance at 280 nm (UV-based yields exceeded $100 \%$ ), which ruled out quantification of the cyclic conjugates from the absorbance of Tyr and/or Trp. ${ }^{14}$ To allow for amino acidindependent cyclic peptide quantification, the molar absorption coefficient of the 4,5-disubstituted CPD ring around $375 \mathrm{~nm}$ was determined $\left(12215 \mathrm{M}^{-1} \mathrm{~cm}^{-1}\right.$ at 373 $\mathrm{nm}$ in water, and $12645 \mathrm{M}^{-1} \mathrm{~cm}^{-1}$ at $365 \mathrm{~nm}$ in methanol) from the UV spectra of solutions of $\mathbf{3 a}$ (quantified by NMR using 1,4-dioxane as internal standard ${ }^{15}$ ).

At that point, more challenging reactions such as those involving CPDs $\mathbf{b}$ and $\mathbf{c}$ and the linear precursor of oxytocin (5) were carried out (Table 1, entries 3-5). 
Table 1. Reaction times and yields for the cyclizations carried out using the first set of fine-tuned conditions ${ }^{\mathrm{a}}$

$\begin{array}{ccccc}\text { entry } & \text { reaction }^{\mathrm{a}} & \text { product } & {\text { time }(\mathrm{h})^{\mathrm{b}}} & \text { yield }(\%)^{\mathrm{c}} \\ 1 & \mathbf{1}+\mathbf{a} & \mathbf{1 a} & 2.75 & 81 \\ 2 & \mathbf{2}+\mathbf{a} & \mathbf{2 a} & 2.25 & 84 \\ 3 & \mathbf{1}+\mathbf{b} & \mathbf{1 b} & 5.5 & 64 \\ 4 & \mathbf{1}+\mathbf{c} & \mathbf{1 c} & 6.5 & 49 \\ 5 & \mathbf{5}+\mathbf{a} & \mathbf{5 a} & 4^{\mathrm{d}} & <30\end{array}$

${ }^{a}$ Cyclization reactions were carried out using protocol 1 (SI, section 4) ${ }^{\mathrm{b}}$ Time needed for the complete disappearance of the corresponding $\mathbf{M}$ 20 Da adduct (the M-22 Da cyclic peptide is then completely formed). ${ }^{\mathrm{c}}$ HPLC-based cyclization yield at that time $(280 \mathrm{~nm})$. Products were not isolated. ${ }^{\mathrm{d}} \mathrm{A}$ large amount of side-products was observed (SI, section 7).

Use of CPD a to cyclize different peptides (1,2 and $\mathbf{5}$, entries 1, 2 and 5 in Table 1) showed that the smallest cycle (19-membered ring, $\mathbf{2}+\mathbf{a}$ reaction) was the one formed more rapidly. Yet, reaction $\mathbf{1}+\mathbf{a}$ was faster than $\mathbf{5}+\mathbf{a}$, which indicates that peptide sequence, in addition to ring size (both reactions afford 22-membered rings in this case), influences the kinetics of the cyclization. Peptides 3 and $\mathbf{4}$, which only differ in the amino acid sequence, were also reacted with CPD a (see SI, section 8). 3 cyclized more rapidly than $\mathbf{4}$, which may suggest that aromatic amino acids adjacent to the $N$-terminal Cys have a negative impact on the cyclization rate.

Reaction rates were also affected by the substituent at the 2 position of the CPD, as shown by the experiments in which peptide $\mathbf{1}$ was reacted with the three CPDs $(\mathbf{a}, \mathbf{b}$ and $\mathbf{c}$, cf. entries 1, 3 and 4 in Table 1). These results suggest that large substituents have a negative impact on cyclization, but this trend is not reproduced by results assembled in Table 2 (see below, entries 3-5 and 10-12).

In all cases longer reaction times correlated with lower cyclization yields, as slower rates cause longer exposure of the internal thiol to the free radical TEMPO, which favors oxidation to sulfonic acid.

To overcome this problem, the effect of a chaotropic agent such as $\mathrm{LiCl}$ in the reaction mixture was evaluated. Here, the troublesome $\mathbf{5}+\mathbf{a}$ reaction was selected as model system. Different amounts of $\mathrm{LiCl}$ were added to the reaction mixture, and the conversion of the M-20 Da adduct to the cyclic product was studied (see SI, section 9). The positive effect of $\mathrm{LiCl}$ was demonstrated, and a clear correlation between the amount of $\mathrm{LiCl}$ and the cyclization rate could be observed. Although the best results were obtained with the highest salt content, a $2 \mathrm{M}$ $\mathrm{LiCl}$ concentration was deemed the best option to accelerate the reaction while reducing possible elution problems during HPLC purification. The cyclization protocol was therefore re-optimized in the presence of $\mathrm{LiCl}$. This resulted in an improved procedure (protocol 2 , section 4 of the SI) in which peptide, CPD and TEMPO (1:1.5:0.2 molar ratio) are incubated at $60{ }^{\circ} \mathrm{C}^{16}$ in $2 \mathrm{M}$ aq. $\mathrm{LiCl}$ for $1 \mathrm{~h} .0 .2$ equiv of TEMPO are then added, and every $30 \mathrm{~min}$ until completion of the reaction (as assessed by HPLC). Cyclizations normally take place in less than $2 \mathrm{~h}$. Solvent composition (water or water/methanol mixtures) has to be adjusted for each CPD on the basis of its solubility.

Protocol 2 was then used to synthesize different cyclic peptides, generally with satisfactory results (Table 2; in the $10+\mathbf{a}$ reaction a longer reaction time was required to attain a satisfactory cyclization yield). Yet, a large amount of contaminants with the same mass and UV profile but different retention times was found to accompany purified compounds $\mathbf{1 b}, \mathbf{1 c}, \mathbf{5 b}$ and $\mathbf{5 c}$ (and other by-products, in the case of $\mathbf{5 b}$ ). Revision of the isolation procedure revealed that these peptides had been lyophilized at the same time as $\mathrm{NH}_{3}$ - or $\mathrm{Et}_{3} \mathrm{~N}$-containing solutions. We surmised that these impurities resulted from epimerization of the $\mathrm{N}$-terminal cysteine, which is likely favored by the high resonance-stabilization of the intermediate anion (see SI, page S2). Studies carried out with peptide 1b showed that the cyclic peptides remained stable while in the reaction crude at room temperature, at acidic $\mathrm{pH}$, and in water or aqueous organic solvents, but not in basic conditions or after prolonged heating.

To confirm the cysteine epimerization hypothesis, the two diastereomers of cyclic peptides $\mathbf{1 b}$ and $\mathbf{7 b}(\mathbf{1}$ and $\mathbf{7}$ differ in the configuration of the $N$-terminal Cys) were isolated. Next, each isomer of $\mathbf{1 b}$ was incubated at $\mathrm{pH}$ 9.0 for $20 \mathrm{~min}$, and the resulting crude analyzed by HPLC. A new compound with the same mass and UV properties had appeared in both cases. Coinjection experiments revealed that each of the newly formed products coeluted with one of the isomers of $\mathbf{7} \mathbf{b}$, thus proving that epimerization had occurred (Figure 2).

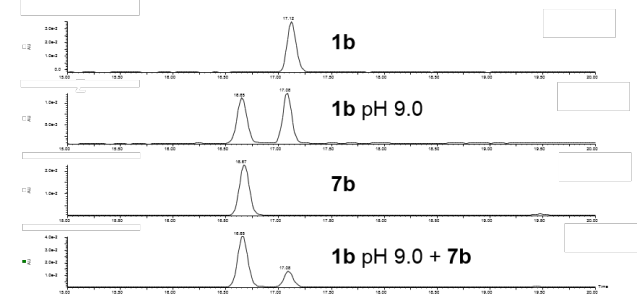

Figure 2. HPLC-MS traces $(280 \mathrm{~nm})$ showing that one of the isomers of $\mathbf{1 b}$ is partially transformed into one of the isomers of $\mathbf{7 b}$ after treatment with a base (AU = absorbance units).

On the basis of these data, D-Cys was employed for the synthesis of different labeled cyclic peptides, which were formed in good yields (see Table 2, entries 8-14), and could be isolated as stereoisomerically pure compounds except in one case.

Additional stability experiments were carried out with each of the two isomers of cyclic peptides $5 \mathbf{a}, 6 \mathbf{6}, 8 \mathbf{8}, 9 \mathbf{a}$ and $9 \mathrm{~b}$ (incubation at $\mathrm{pH} 7.4 \mathrm{PBS}$ buffer for 12 and $24 \mathrm{~h}$, and at $\mathrm{pH} 9.0$ for $20 \mathrm{~min}$ ). HPLC monitoring revealed that the epimerization extent was largely compounddependent, although in general L-Cys-containing 
Table 2. Reaction yields for the cyclization and derivatization reactions carried out using the finally optimised procedure, and stability of the isolated products to bases

\begin{tabular}{|c|c|c|c|c|c|c|c|c|c|c|c|}
\hline \multicolumn{6}{|c|}{ Peptides containing L-Cys at the $N$-terminal position } & \multicolumn{6}{|c|}{ Peptides containing D-Cys at the $N$-terminal position } \\
\hline \multirow[t]{2}{*}{ entry } & \multirow[t]{2}{*}{ reaction $^{\mathrm{a}}$} & \multirow[t]{2}{*}{ product } & \multirow{2}{*}{$\begin{array}{l}\text { yield } \\
(\%)^{b}\end{array}$} & \multicolumn{2}{|c|}{$\begin{array}{l}\text { non-epimerized } \\
\text { product }(\%)^{c}\end{array}$} & \multirow[t]{2}{*}{ entry } & \multirow[t]{2}{*}{ reaction $^{\mathrm{a}}$} & \multirow[t]{2}{*}{ product } & \multirow{2}{*}{$\begin{array}{l}\text { yield } \\
(\%)^{b}\end{array}$} & \multicolumn{2}{|c|}{$\begin{array}{l}\text { non-epimerized } \\
\text { product }(\%)^{\mathrm{c}}\end{array}$} \\
\hline & & & & isomer 1 & isomer 2 & & & & & isomer 1 & isomer 2 \\
\hline 1 & $\mathbf{1}+\mathbf{b}$ & 1b & $76 / 34$ & 64 & 83 & 8 & $7+b$ & $7 \mathrm{~b}$ & $76 / 40$ & 95 & 93 \\
\hline 2 & $1+\mathbf{c}$ & 1c & $75 / 37$ & n.d. & n.d. & 9 & $7+\mathbf{c}$ & $7 \mathrm{c}$ & $66 / 40$ & n.d. & n.d. \\
\hline 3 & $5+\mathbf{a}$ & 5a & 80 & 87 & 6 & 10 & $8+\mathbf{a}$ & 8a & 72 & 94 & 99 \\
\hline 4 & $\mathbf{5}+\mathbf{b}$ & $\mathbf{5 b}$ & 65 & n.d. & n.d. & 11 & $\mathbf{8}+\mathbf{b}$ & $\mathbf{8 b}$ & $77 / 33$ & n.d. & n.d. \\
\hline 5 & $5+\mathbf{c}$ & $5 c$ & $84 / 33$ & n.d. & n.d. & 12 & $8+\mathbf{c}$ & $8 c$ & $82 / 45$ & n.d. & n.d. \\
\hline 6 & $6+a$ & $6 a$ & $36^{\mathrm{d}}$ & 45 & 59 & 13 & $9+\mathbf{a}$ & $9 a$ & 63 & 54 & 40 \\
\hline 7 & $6+b$ & $6 \mathrm{~b}$ & $25^{\mathrm{d}}$ & n.d. ${ }^{\mathrm{e}}$ & n.d. ${ }^{\mathrm{e}}$ & 14 & $\mathbf{9}+\mathbf{b}$ & $9 \mathbf{b}^{\mathrm{f}}$ & $74 / 22$ & 100 & 36 \\
\hline & & & & & & 15 & $10+a$ & 10a & $68 / 47^{g}$ & n.d. & n.d. \\
\hline
\end{tabular}

${ }^{\mathrm{a}}$ Cyclization reactions were carried out using protocol 2 (SI, section $4 ; 2 \mathrm{~h}$ reaction time). Water was used as solvent except in experiments corresponding to entries 2, 4, 5, 9 and 12, where a 1:1 MeOH/ $\mathrm{H}_{2} \mathrm{O}$ mixture was employed. ${ }^{b} \mathrm{HPLC}$-based cyclization yield after $2 \mathrm{~h}$ (280 nm)/Isolated yield (after HPLC purification, SI section 11). ${ }^{\mathrm{c}}$ Stability determined at $\mathrm{pH} 7.4$ after $12 \mathrm{~h}$ incubation (n.d. = not determined). ${ }^{\mathrm{d}}$ Several side reactions took place upon cyclization of peptide $6 .{ }^{\mathrm{e}}$ These products could not be isolated due to the complexity of the crude. ${ }^{\mathrm{f}}$ Isomer 2 of product $9 \mathrm{~b}$ was isolated as a mixture of epimers at the $N$-terminal Cys. ${ }^{\mathrm{g}}$ Reaction time was $3.5 \mathrm{~h}$ in this case (total amount of TEMPO: 1.4 equiv).

products tended to epimerize faster than those containing D-Cys. Table 2 shows that the amount of non-epimerized product is usually higher for the peptides with D-Cys than for those with L-Cys (cf. entries 1 and 8, 3 and 10, and 6 and 13; see SI, section 10). Even though it yields stereoisomeric compounds, we believe that this methodology may find application, since synthetic methods providing mixtures of isomers have found use in bioconjugation (inverse electron demand Diels-Alder cycloadditions, reactions between azides and strained cyclooctynes) and in therapy (three phosphorothioate oligonucleotides have been approved as drugs).

In conclusion, this work has demonstrated that CPDs can be used to simultaneously cyclize and derivatize peptides with two cysteine residues, of which one at the $N$-terminus. This should not be a limitation, since several methods (including SPPS) allow this residue to be introduced into peptides and proteins. ${ }^{17}$

Cyclizations have furnished 19-, 22-, 25 and 31membered rings, and take place in good yields and relatively short reaction times using TEMPO as catalyst and in the presence of $\mathrm{LiCl}$. Different data (MS, UV, and also NMR) have confirmed that cyclization does take place.

Structural parameters affecting the reaction rate and outcome as well as the stability of the conjugated cyclic peptides to bases have been examined. Our results point to peptide sequence as influencing the cyclization kinetics, and show that peptides with D-Cys at the $N$ terminus furnish cycles generally more stable. For this reason, introduction of D-Cys at the $N$-terminal position is recommended. However, structural studies out of the scope of this work should be performed to establish the ultimate reasons behind the observation that both the CPD and peptide nature have a profound effect on the reaction rate, as well as the different chemical behavior of the L- and D-epimers.
Acknowledgments. This work was supported by funds from the Ministerio de Economía y Competitividad (grant CTQ2014-52658-R). O. B. was a recipient fellow of the MINECO (FPI). L. A. research placement in Barcelona was supported by the Erasmus programme.

Supporting Information Available. Experimental procedures, compound characterization data and HPLC profiles. This material is available free of charge via the Internet at http://pubc.acs.org./

\section{References and notes}

(1) Luo, J.; Abrahams, J. P. Chem.-Eur. J. 2014, 20, 2410.

(2) Mogi, T.; Kita, K. Cell. Mol.Life Sci. 2009, 66, 3821.

(3) Guo, J.; Hu, H.; Zhao, Q.; Wang, T.; Zou, Y.; Yu, S.; Wu, Q.; Guo, Z. ChemMedChem 2012, 7, 1496.

(4) Wolin, E. M. Gastrointest. Cancer Res. GCR 2012, 5, 161.

(5) Hill, T. A.; Shepherd, N. E.; Diness, F.; Fairlie, D. P. Angew. Chem. Int. Ed. 2014, 53, 13020.

(6) Nischan, N.; Herce, H. D.; Natale, F.; Bohlke, N.; Budisa, N.; Cardoso, M. C.; Hackenberger, C. P. R. Angew. Chem. Int. Ed. 2015, 54, 1950.

(7) Choi, H. S.; Gibbs, S. L.; Lee, J. H.; Kim, S. H.; Ashitate, Y.; Liu, F.; Hyun, H.; Park, G.; Xie, Y.; Bae, S.; Henary, M.; Frangioni, J. V. Nat. Biotechnol. 2013, 31, 148.

(8) Danhier, F.; Breton, A. L.; Préat, V. Mol. Pharm. 2012, 9, 2961. (9) (a) Dewkar, G. K.; Carneiro, P. B.; Hartman, M. C. T. Org. Lett. 2009, 11, 4708. (b) Smeenk, L. E. J.; Dailly, N.; Hiemstra, H.; van Maarseveen, J. H.; Timmerman, P. Org. Lett. 2012, 14, 1194. (c) Demeter, O.; Fodor, E. A.; Kállay, M.; Mező, G.; Németh, K.; Szabó, P. T.; Kele, P. Chem.-Eur. J. 2016, 22, 6382. (d) Kuan, S. L.; Wang, T.; Weil, T. Chem.-Eur. J. 2016, 22, 17112 (and references cited therein).

(10) Brun, O.; Agramunt, J.; Raich, L.; Rovira, C.; Pedroso, E.; Grandas, A. Org. Lett. 2016, 18, 4836.

(11) (a) Viero, C.; Shibuya, I.; Kitamura, N.; Verkhratsky, A.; Fujihara, H.; Katoh, A.; Ueta, Y.; Zingg, H. H.; Chvatal, A.; Sykova, E.; Dayanithi, G. CNS Neurosci. Ther. 2010, 16, e138. (b) Kemp, A. H.; Guastella, A. J. Curr. Dir. Psychol. Sci. 2011, 20, 222.

(12) Podstawka, E. J. Raman Spectrosc. 2008, 39, 1290.

(13) (a) Stolz, R. M.; Northrop, B. H. J. Org. Chem. 2013, 78, 8105. (b) Northrop, B. H.; Coffey, R. N. J. Am. Chem. Soc. 2012, 134, 13804. (c) Hoyle, C. E; Bowman, C. N. Angew. Chem. Int. Ed. 2010, $49,1540$.

(14) Schmid, F.-X. 2001. Biological Macromolecules: UV-visible Spectrophotometry. In eLS. John Wiley \& Sons, Ltd, Chichester. 
(15) (a) Bharti, S. K.; Roy, R. TrAC Trends Anal. Chem. 2012, 35, 5. (b) Yang, Q.; Qiu, H.; Guo, W.; Wang, D.; Zhou, X.; Xue, D.; Zhang, J.; Wu, S.; Wang, Y. Molecules 2015, 20, 12114. (c) Tanaka, R.; Shibata, H.; Sugimoto, N.; Akiyama, H.; Nagatsu, A. J. Nat. Med. 2016, $70,797$.

(16) Additional $\mathbf{1}+\mathbf{a}$ and $\mathbf{5}+\mathbf{a}$ experiments revealed that cyclization reactions can also be performed at $37^{\circ} \mathrm{C}$, but longer reaction times are required to reach the same yields. Therefore $60{ }^{\circ} \mathrm{C}$ was the temperature of choice in all subsequent experiments.

(17) (a) Gentle, I. E.; De Souza, D. P.; Baca, M. Bioconjug. Chem. 2004, 15, 658. (b) Ren, H.; Xiao, F.; Zhan, K.; Kim, Y.-P.; Xie, H.; Xia, Z.; Rao, J. Angew. Chem. Int. Ed. 2009, 48, 9658. (c) Tolbert, T. J.; Wong, C.-H. Angew. Chem. Int. Ed. 2002, 41, 2171. 